\title{
A comparative study of Water Quality Index (WQI) of Peruvanthanam and Valiyathodu sub-watersheds of Manimala river basin, Kerala, South India.
}

\author{
V. B. Rekha ${ }^{1, *}$, A. V. George ${ }^{2}$ and M. Rita ${ }^{3}$ \\ ${ }^{1}$ School of Environmental Science, Mahatma Gandhi University, Kottayam, Kerala, India. \\ ${ }^{2}$ Department of Environmental Science, Central University of Kerala, Vidhyanagar. PO, Kasargode. \\ ${ }^{3}$ Department of Chemistry, Government Engineering College, Thrissur, Kerala, India.
}

\begin{abstract}
Water Quality Index (WQI) is the rating that reflects the composite influence of different water quality parameters such as $\mathrm{pH}, T D S$, Hardness, Sulphate, Chloride and Turbidity. WQI has been classified as excellent, good, fair, marginal and poor.Thematic maps for the study area were prepared from SOI toposheets and IRS P6 LISS-III image $\left(P_{100} / R_{67}\right)$ using Arc GIS 9.2 software.WQI values were added as attribute data and spatial distribution maps for both sub-watersheds were prepared. Critical analysis and comparison of WQI for both sub-watersheds reveals that, during monsoon period, Peruvanthanam has maximum 'excellent' category ie, $47.06 \%$ than Valiyathodu sub-watershed ie, 33.33\%. 'excellent' ie, 23.52\%, 'good' ie, 29.41\% and 'fair' ie, $47.06 \%$ during pre monsoon, 'good' ie, $35.29 \%$ and 'fair' ie,17.65\% during monsoon and 'excellent' ie, $17.65 \%$ 'good' ie, $23.53 \%$ and 'fair' ie, $58.82 \%$ during post monsoon season. Valiyathodu sub-watershed has 'excellent' ie, $26.67 \%$, 'good' ie, $33.33 \%$ and 'fair' ie, $40.00 \%$ during pre monsoon. It shows constant value of $40.00 \%$ for good category during monsoon and post monsoon season. WQI having fair value of $6.67 \%$ and $33.33 \%$ for monsoon and post monsoon seasons respectively. Marginal category for monsoon and post monsoon season is $20.00 \%$ and $26.67 \%$ respectively. Hence it is explicit that, in general water quality is good in Peruvanthanam sub-watershed, compared to Valiyathodu sub-watershed.
\end{abstract}

Keywords - Arc GIS.9.2, IRS P6 LISS-III image $\left(P_{100} / R_{67}\right)$, SOI toposheet, Spatial distribution Water Quality Index (WQI)

\section{INTRODUCTION}

Ground water has become an essential resource over the past few decades due to the increased usage for drinking, irrigation, industrial and other uses [1]. The quality of water is equally important to that of quantity. Watersheds are significant to every region as it provides drinking water, water for irrigation, recreation and industrial activities. Study of the water quality of sub-watersheds are also of great significance because any change in water quality of a portion of a watershed can drastically affect the entire drainage basin. River Manimala, draining through both the study areas ie, Peruvanthanam and Valiyathodu sub-watershed, are perennial in nature. It has a total yield of $1829 \mathrm{~mm}^{3}$ and annual utilizable yield is $1108 \mathrm{~mm}^{3}$ [2]. Since fertilizer applications in Rubber plantations of both sub-watersheds is a common practice, the suitability of groundwater for drinking and other purposes are to be ascertained. Hence a comparative study of WQI of both subwatersheds is of much significance for better understanding of quality of water and future management plans for restoration of already affected watersheds to their natural state through systematic monitoring of pollution and implementation of regulations to reduce further pollution.

\section{STUDY AREA}

The areas selected for the present investigation ie, Peruvanthanam and Valiyathodu sub-watersheds belongs to a typical highland and midland sub-watershed of the Manimala river basin. The Peruvanthanam subwatershed (Fig.1a) lies between $9^{0} 29^{\prime} 00^{\prime \prime}$ to $9^{0} 34^{\prime} 00^{\prime \prime} \mathrm{N}$ latitude and $76^{\circ} 53^{\prime} 00^{\prime \prime}$ to $76^{\circ} 59^{\prime} 00^{\prime \prime}$ E longitude. The Valiyathodu sub-watershed (Fig.1b) lies between $9^{0} 30^{\prime} 00^{\prime \prime}$ to $9^{0} 37^{\prime} 00^{\prime \prime} \mathrm{N}$ latitude and $76^{\circ} 41^{\prime} 00^{\prime \prime}$ to $76^{\circ} 46^{\prime} 00^{\prime \prime} \mathrm{E}$ longitude. Peruvanthanam sub-watershed covers an area of $56.42 \mathrm{~km}^{2}$ and Valiyathodu, $54.85 \mathrm{~km}^{2}$. 


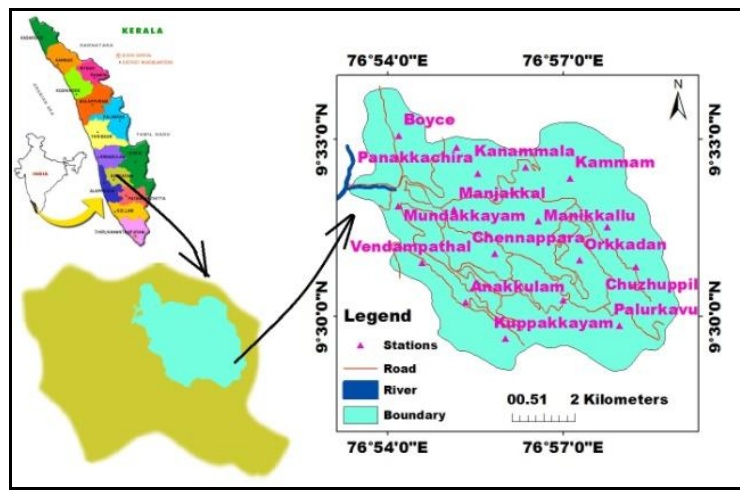

(a)

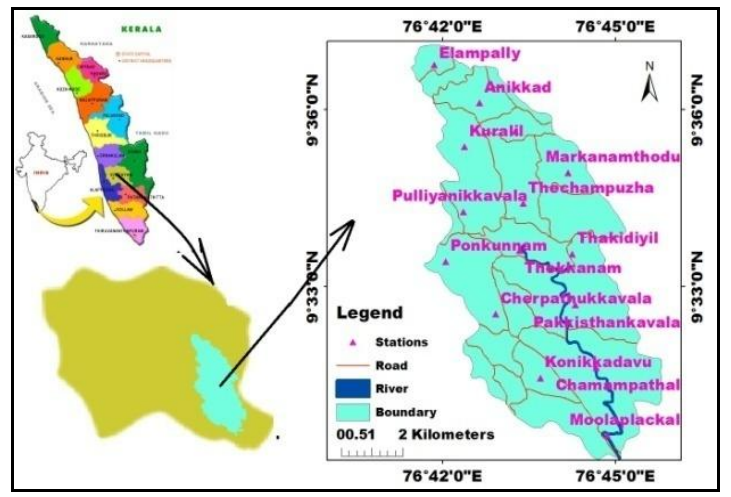

(b)

Figure 1.Location maps (a) Location map of Peruvanthanam sub-watershed (b) Location map of Valiyathodu sub-watershed

\section{METHODOLOGY}

The integrated status of various water quality parameters that are relevant and significant to particular use is reflected in WQI. It is an effective way to communicate information about the quality of water and it provides a single number that expresses the overall water quality status at a certain location and time. The most important factor in determining the WQI is the selection of water quality parameters. Influence of water quality parameters on pollution depends on the permissible levels suggested by BIS [3]. Parameters having low permissible limits will be given high weightage as they are harmful to the quality of water to a great extent on slight increase in value [4]. Thus high weightage is given to these factors. Parameters having higher permissible limits are less harmful and less weightage [5].

Thus, $\mathrm{WQI}=\mathrm{Wi} \times \mathrm{Vr} ; \mathrm{Wi}=\mathrm{K} / \mathrm{Vi}$

$\mathrm{Wi}=$ Unit weight of chemical factor

$\mathrm{K}=$ Constant of proportionality; $\mathrm{Vi}=$ Permissible level

$\mathrm{K}=1 / \Sigma 1 / \mathrm{Vi} ; \Sigma 1 / \mathrm{Vi}=1 / \mathrm{V}(\mathrm{pH})+1 / \mathrm{V}(\mathrm{TDS})+\ldots \ldots . . \mathrm{n}$ (parameters)

$\mathrm{WQI}=\mathrm{Wi} \mathrm{x} \mathrm{Vr}$

$\mathrm{Wi} \times \mathrm{Vr}=\mathrm{Wi}(\mathrm{pH}) \times \mathrm{Vr}(\mathrm{pH})+\mathrm{Wi}(\mathrm{TDS}) \mathrm{x} \operatorname{Vr}(\mathrm{TDS})+-\mathrm{n}$ (parameters)

Wi proportional to $1 / \mathrm{Vi}$

The rating scale ranges from 0 to 100 . For the better interpretation we can divide these ranges into different classes,

i.e., $\mathrm{Vr}=0$, water that is highly polluted; $\mathrm{Vr}=100$, water that is absolutely clean. Medium values represent intermediate pollution conditions of water. Water quality factors, their standards and assigned unit weights are given in table.1. Rating values for different factors to calculate WQI are shown in the table.2.

Table 1: Water quality factors and assigned unit weights

\begin{tabular}{cccc}
\hline Si. & Vi (BIS & Wi (Unit \\
No & Parameters & STD) & Weights) \\
\hline 1 & pH & $<7-8.5>$ & 0.530 \\
2 & TDS & $<500 \mathrm{mg} / 1$ & 0.008 \\
3 & Hardness & $<300 \mathrm{mg} / 1$ & 0.014 \\
4 & Chloride & $<250 \mathrm{mg} / 1$ & 0.016 \\
5 & Sulphate & $<200 \mathrm{mg} / 1$ & 0.021 \\
6 & Turbidity & $<10 \mathrm{NTU}$ & 0.411 \\
\hline
\end{tabular}

Table 2: Rating for different factors to calculate WQI

\begin{tabular}{cccccc}
\hline Parameter & \multicolumn{5}{c}{ Ranges } \\
\hline pH & $7-8.5$ & $6.80-6.99$ & $6.60-6.79$ & $6.39-6.59$ & $<6.4$ \\
& & & & & $>500$ \\
TDS & $0-50$ & $50.1-100$ & $100.1-150$ & $150.1-500$ & $>300$ \\
Hardness & $0-50$ & $50.1-100$ & $100.1-150$ & $150.1-300$ & $>250$ \\
Chloride & $0-62.5$ & $62.6-125$ & $125.1-187.5$ & $187.6-250$ & $>200$ \\
Sulphate & $0-50$ & $50.1-100$ & $100.1-150$ & $150.1-200$ & $>10$ \\
Turbidity & $0-2.5$ & $2.6-5$ & $5.1-7.5$ & $7.6-10$ & $>10$ \\
Ratings $(\mathbf{V r})$ & 100 & 80 & 60 & 40 & 0 \\
\hline
\end{tabular}


In the present investigation, to find out WQI, physico-chemical parameters such as pH, TDS, Hardness, Chloride, Sulphate and Turbidity [6] and [7] were used. Values of Vi, Wi and Vr are given in table.1 and table.2. WQI is basically a mathematical way of calculating a single value from multiple test results [8]. The word 'weighting' implies the relative significance of each of the above mentioned physico-chemical parameters in overall quality of water and is dependent on the permissible levels of drinking water [3]. Classifications of WQI using different designations are given in table.3. Considerable variations are observed during different seasons in both sub-watersheds. These variations are discussed sub-watershed wise and season wise in the following sections.

Table 3: Classification of WQI

\begin{tabular}{cccc}
\hline WQI & Water Quality & Class & Designation \\
\hline$<100$ & Excellent & Class 1 & Absolutely clean \\
$60-80$ & Good & Class 1 & Slightly unclean \\
$40-60$ & Fair & Class 2 & Moderately unclean \\
$20-40$ & Marginal & Class 2 & Excessively unclean \\
$0-20$ & Poor & Class 3 & Severely unclean \\
\hline
\end{tabular}

IV. RESULT AND DISCUSSION

Variations in mean value of WQI during pre monsoon, monsoon and post monsoon seasons for Peruvanthanam sub-watershed are represented in table 4. During pre monsoon season mean WQI varies between 47.00 and 89.40. During monsoon the variations are from 47.00 to 98.78 and during post monsoon from 45 to 90.40. The highest mean value of WQI for all the three seasons is 92.53, reported from the sample station P3 and the lowest mean value of WQI for all the three seasons ie, 47 is reported from P6. The seasonal variations in mean value of WQI of Peruvanthanam sub-watershed is represented in fig. $2 \mathrm{a}$

The variations in mean value of WQI during pre monsoon, monsoon and post monsoon seasons of Valiythodu sub-watershed are represented in table 5. During pre monsoon season WQI values varies from 47 to 89.40 and in monsoon from 31.68 to 97.71 . During post monsoon the corresponding variations in WQI are from 38.78 to 78.80. The highest mean value WQI for different seasons together ie, 88.64 is reported from the sample station V5 and the lowest mean value 39.15 from V7. The seasonal variation in mean value of WQI of Valiyathodu sub-watershed is represented in fig. $2 \mathrm{~b}$.

According to the classification of WQI during pre monsoon season sample stations of Peruvanthanam sub-watershed, P3, P8, P9 and P15 comes under excellent category ie, class 1/ absolutely clean (23.52\%) (Fig.3 a and Fig.4a). P11, P12, P13, P14 and P17 ie, 29.41\% comes under the good category ie, class 1/ slightly unclean and sample stations, P1, P2, P4, P5, P6, P7, P10 and P16 comes under the fair category ie, class 2/ moderately unclean (47.06\%). During monsoon season, stations P3, P5, P7, P9, P10, P13, P15 and P16 ie, 47.06 $\%$ come under excellent category ie, class 1/ absolutely clean. P2, P4, P8, P11, P14 and P17 ie, 35.29\% comes under good category ie, class 1/ slightly unclean. P1, P6 and P12 ie, 17.65\%.comes under fair category class 2/ moderately unclean (Fig.3b and Fig.4b). During post monsoon season, stations namely P3, P13 and P15 ie, $17.65 \%$ comes under excellent category ie, class $1 /$ absolutely clean. P4, P5, P7 and P9 ie, 23.53\% comes under good category ie, class 1/ slightly unclean. P1, P2, P6, P8, P10, P11, P12, P14, P16 and P17 ie, 58.82\% comes under fair category ie, class $2 /$ moderately unclean (Fig.3c and Fig.4c).

Table 4: WQI for Peruvanthanam

Sub-watershed

\begin{tabular}{|c|c|c|c|c|c|}
\hline \multirow[t]{2}{*}{$\mathbf{N}$} & \multirow[t]{2}{*}{$\mathbf{S}$} & \multicolumn{4}{|c|}{ Water Quality Index } \\
\hline & & $\mathbf{1}$ & 2 & 3 & Mean \\
\hline \multirow{8}{*}{$\begin{array}{l}\text { 总 } \\
\text { 总 } \\
\text { 总 } \\
\text { 总 }\end{array}$} & P1 & 47.00 & 58.78 & 47.00 & 50.93 \\
\hline & P2 & 47.00 & 78.78 & 47.00 & 57.59 \\
\hline & P3 & 89.40 & 98.78 & 89.40 & 92.53 \\
\hline & P4 & 47.00 & 77.00 & 78.80 & 67.60 \\
\hline & P5 & 47.00 & 88.78 & 78.80 & 71.53 \\
\hline & P6 & 47.00 & 47.00 & 47.00 & 47.00 \\
\hline & P7 & 47.00 & 87.00 & 78.80 & 70.93 \\
\hline & P8 & 89.40 & 77.00 & 45.00 & 70.47 \\
\hline \multirow{9}{*}{ 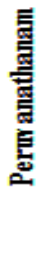 } & P9 & 88.80 & 97.00 & 78.80 & 84.87 \\
\hline & P10 & 47.00 & 88.78 & 47.00 & 60.93 \\
\hline & P11 & 68.20 & 68.78 & 47.00 & 61.33 \\
\hline & P12 & 68.20 & 47.00 & 47.00 & 54.07 \\
\hline & $\mathbf{P 1 3}$ & 78.80 & 88.78 & 90.40 & 85.99 \\
\hline & P14 & 78.80 & 78.78 & 47.00 & 68.19 \\
\hline & P15 & 89.40 & 88.78 & 81.18 & 86.45 \\
\hline & P16 & 47.00 & 87.00 & 47.00 & 60.33 \\
\hline & P17 & 78.80 & 78.78 & 47.00 & 68.19 \\
\hline
\end{tabular}

Table 5: WQI for Valiyathodu sub-watershed

\begin{tabular}{|c|c|c|c|c|c|}
\hline \multirow[t]{2}{*}{$\mathbf{N}$} & \multirow[t]{2}{*}{$\mathbf{s}$} & \multicolumn{4}{|c|}{ Water Quality Index } \\
\hline & & 1 & 2 & 3 & Mean \\
\hline \multirow{15}{*}{ 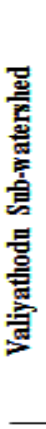 } & V1 & 47.00 & 81.75 & 47.00 & 58.58 \\
\hline & V2 & 47.00 & 67.00 & 47.00 & 53.67 \\
\hline & V3 & 47.00 & 47.00 & 78.80 & 57.60 \\
\hline & V4 & 68.20 & 68.78 & 47.00 & 61.33 \\
\hline & V5 & 89.40 & 97.71 & 78.80 & 88.64 \\
\hline & v6 & 68.20 & 62.72 & 38.78 & 56.57 \\
\hline & V7 & 47.00 & 31.68 & 38.78 & 39.15 \\
\hline & V8 & 47.00 & 88.78 & 38.78 & 58.19 \\
\hline & V9 & 47.00 & 38.78 & 70.58 & 52.12 \\
\hline & V10 & 89.40 & 91.12 & 78.80 & 86.44 \\
\hline & V11 & 68.20 & 87.00 & 47.00 & 67.40 \\
\hline & V12 & 89.24 & 38.78 & 78.80 & 68.94 \\
\hline & V13 & 89.40 & 78.78 & 47.00 & 71.73 \\
\hline & V14 & 68.20 & 62.78 & 38.78 & 56.59 \\
\hline & V15 & 78.80 & 78.78 & 59.98 & 72.52 \\
\hline
\end{tabular}

$1=$ Pre monsoon;2=Monsoon;3=Post monsoon 


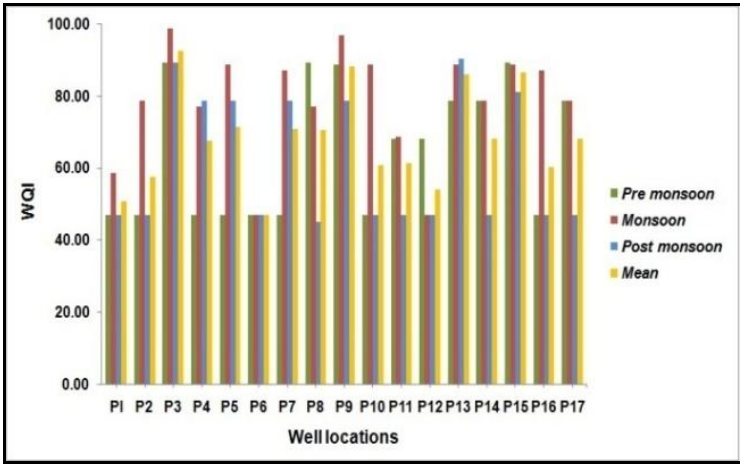

(a)

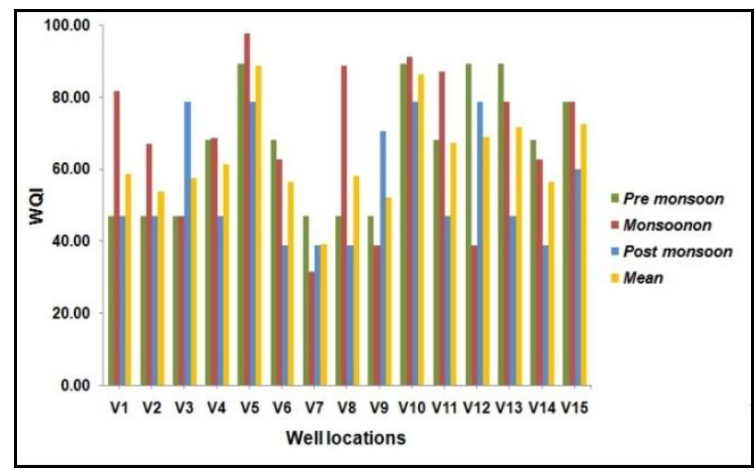

(b)

Figure 2. Seasonal variations in mean WQI (a) Seasonal variations in mean WQI in Peruvanthanam sub-watershed (b) Seasonal variations in mean WQI in Valiyathodu sub-watershed

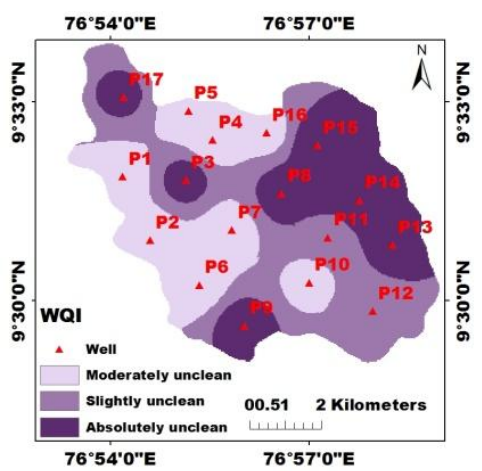

(a)

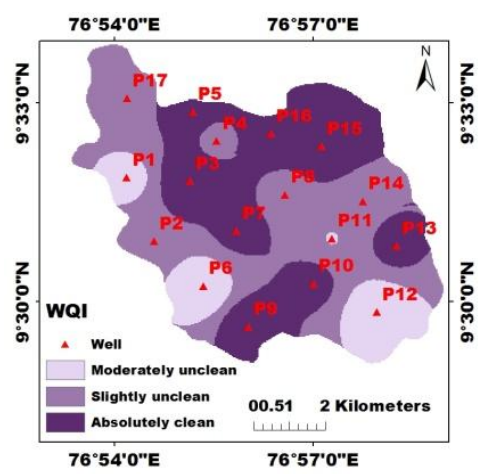

(b)

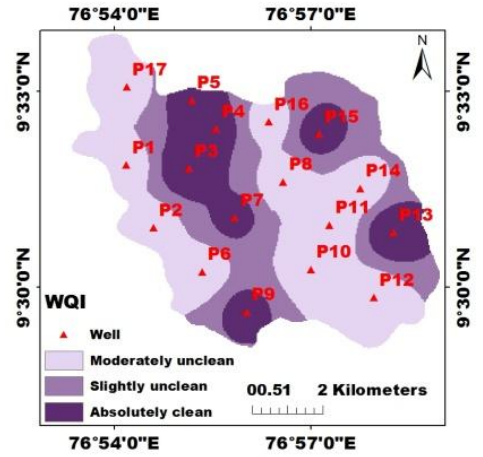

(c)

Figure 3. Variations in mean value of WQI of Peruvanthanam sub-watershed during different seasons (a) Variations in mean value of WQI of Peruvanthanam sub-watershed during pre monsoon

(b) Variations in mean value of WQI of Peruvanthanam sub-watershed during monsoon (c) Variations in mean value of WQI of Peruvanthanam sub-watershed during post monsoon

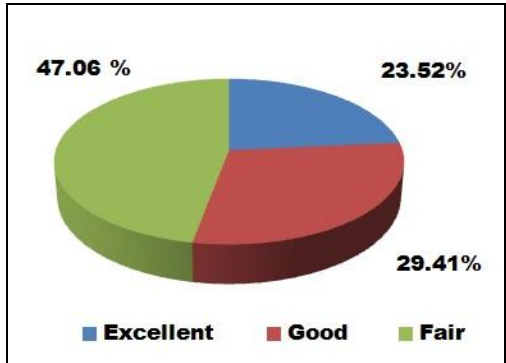

(a)

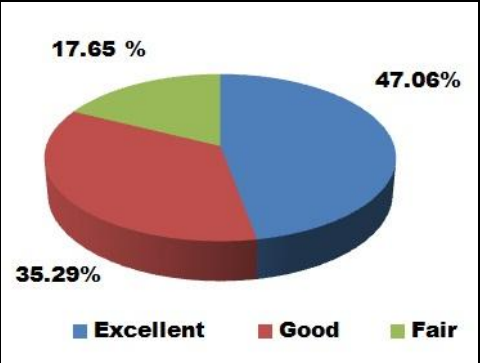

(b)

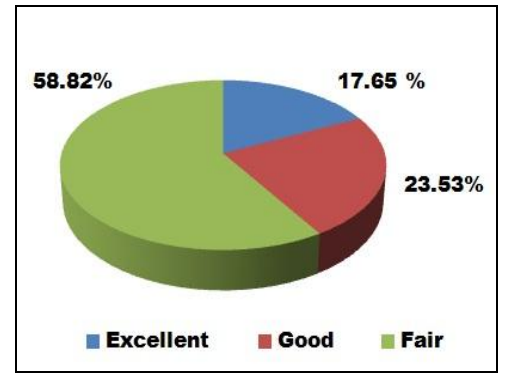

(c)

Figure 4. Classification of WQI of Peruvanthanam sub-watershed during different seasons (a)

Classification of WQI of Peruvanthanam sub-watershed during pre monsoon (b) Classification of WQI of Peruvanthanam sub-watershed during monsoon (C) Classification of WQI of Peruvanthanam sub-watershed during post monsoon

In Valiyathodu sub-watershed according to the classification of WQI during pre monsoon sample stations V5, V10, V12 and V13 ie, 26.67\% comes under excellent category ie, class 1/ absolutely clean. V4, V6, V11and V14 ie, 33.33\% comes under the good category ie, class $1 /$ slightly unclean V1, V2, V3, V7, V8 and V9 ie, $40.00 \%$ comes under the fair category ie, class $2 /$ moderately unclean (Fig. 5a and Fig. 6a). During monsoon season, stations namely V1, V5, V8, V10, and V11 ie, 33.33\% come under excellent category ie, class 1/ absolutely clean. V2, V4, V6, V13, V14 and V15 ie. $40.00 \%$ comes under good category ie, class $1 /$ slightly unclean, V3 6.67\% comes under fair category ie, class2/ moderately unclean and V7, V9 and V12 ie, $20.00 \%$ comes under marginal category ie, class $2 /$ excessively unclean (Fig. 5b and Fig. 6b). During post monsoon season, stations V3, V5, V10 and V12 ie, 40.00\% comes under good category ie, class1/ slightly unclean.V1, 
V2, V4, V11 and V13 ie, 33.33\% comes under fair category ie, class 2/ moderately unclean and V6, V7, V8 and V14 ie, $26.67 \%$ comes under marginal category ie, class2/ excessively unclean (Fig.5c and Fig.6c).

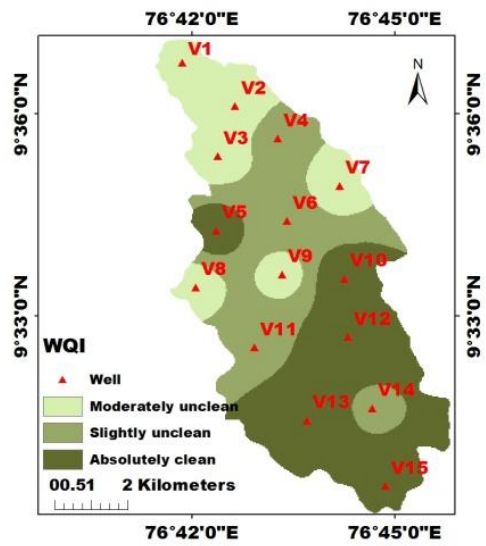

(a)

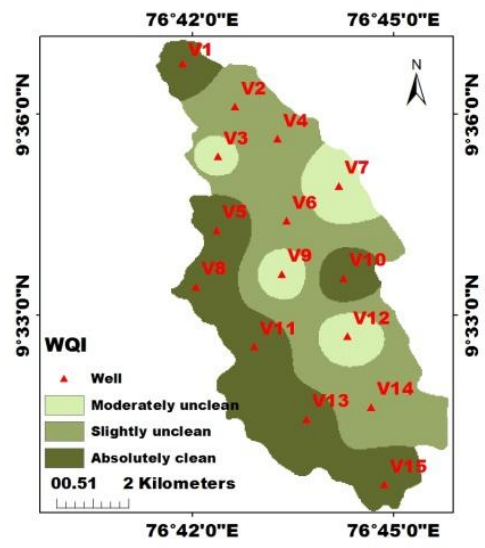

(b)

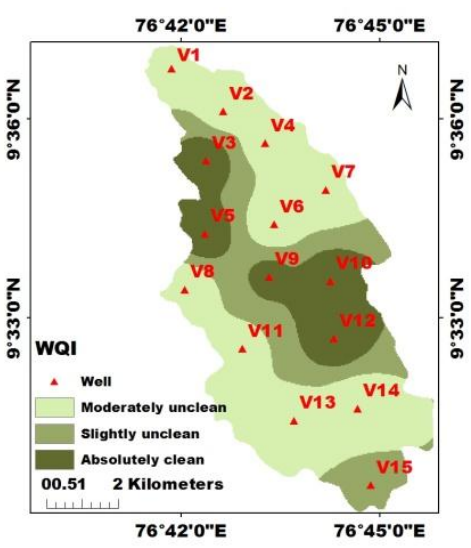

(c)

Figure 5. Variations in mean value of WQI of Valiyathodu sub-watershed during different seasons

(a) Variations in mean value of WQI of Valiyathodu sub-watershed during pre monsoon (b)

Variations in mean value of WQI of Valiyathodu sub-watershed during monsoon (c) Variations in mean value of WQI of Valiyathodu sub-watershed during post monsoon

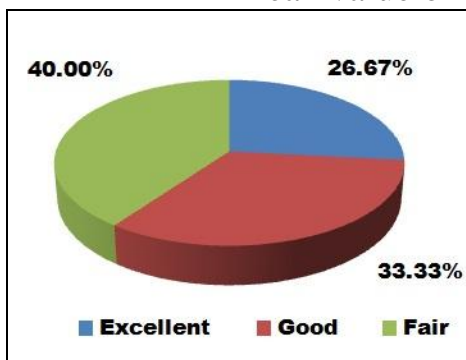

(a)

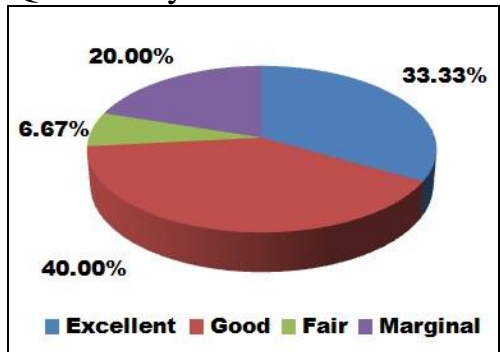

(b)

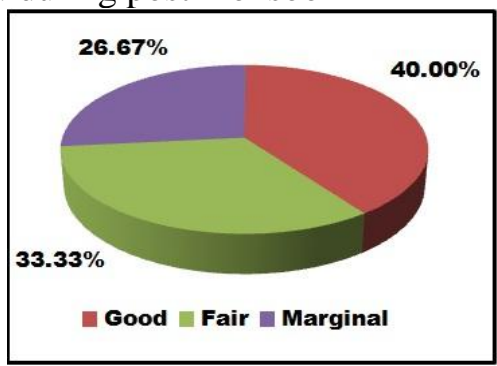

(c)

Figure 6. Classification of WQI of Valiyathodu sub-watershed during different seasons (a) Classification of WQI of Valiyathodu sub-watershed during pre monsoon (b) Classification of WQI of Valiyathodu sub-watershed during monsoon (c) Classification of WQI of Valiyathodu subwatershed during post monsoon

\section{CONCLUSION}

Comparison of Water Quality Index (WQI) between Peruvanthanam and Valiyathodu sub-watershed shows that in both sub-watersheds, percentage of excellant category is higher during monsoon season compared to other seasons. It is further noticed that , in comparison to Valiyathodu sub-watershed ie, 33.33\%, Peruvanthanam sub-watershed has maximum 'excellent' category ie, $47.06 \%$ during monsoon, 'excellent' ie, $23.52 \%$, 'good' ie, $29.41 \%$ and 'fair' ie, $47.06 \%$ during pre monsoon, 'good' ie, $35.29 \%$ and 'fair' ie, $17.65 \%$ during monsoon and 'excellent' ie, $17.65 \%$ 'good' ie, $23.53 \%$ and 'fair' ie, $58.82 \%$ during post monsoon season. Valiyathodu sub-watershed has 'excellent' ie, $26.67 \%$, 'good' ie, $33.33 \%$ and 'fair' ie, $40.00 \%$ during pre monsoon. It shows constant value of $40.00 \%$ for good category during monsoon and post monsoon season. WQI having fair value of $6.67 \%$ and $33.33 \%$ for monsoon and post monsoon seasons respectively. Marginal category for monsoon and post monsoon season is $20.00 \%$ and $26.67 \%$ respectively. From these observations it can be concluded that the monsoon recharge is playing an important role in keeping the quality of water in good condition in both Peruvanthanam and Valiyathodu sub-watershed. Hence it is explicit that, in general water quality is good in Peruvanthanam sub-watershed, compared to Valiyathodu sub-watershed.

\section{Acknowledgements}

The authors gratefully acknowledge the Director, School of Environmental Science, MG University, Kottayam and Head of the Department of Central University of Kerala, Kasargode, for the support extended and facilities provided during the course of study. 


\section{REFERENCES}

[1] S.S. Asadi, P. Vuppala, M.A. Reddy, Remote Sensing and GIS techniques for evaluation of groundwater quality in Municipal Corporation of Hyderabad (Zone-V), India, International Journal of Environmental Research and Public Health. 4(1), $2007,45-52$.

[2] CWRDM. Water Atlas of Kerala, Centre for Water Resources Development and Management, (Government of Kerala, Thiruvananthapuram, Kerala,1995).

[3] BIS. Indian standards Institution- Indian Standard Specification for drinking water (ISO.10500, First revision,1991).

[4] S. Iwata, T. Tabuchi, B. Warkentin, Soil water interactions; Mechanisms and Applications (Marcel Dekker, Inc, Newyork, 1998)

[5] S. P. Pande, M. Z. Hasan, K. L. Saxena, Nitrates and Nitrites in the environment, Journal of Indian Water Work Association. 18(3). 1986.

[6] R. N. Mc Nelly, I.P. Nemenia, L. A. Dwyer, Guide to water quality parameters, (Inland Water Directorate, v.1, Canada. 1979).

[7] J. K. Fawell, D. G. Miller, Drinking water quality and the consumer, Journal of Chartered Institution for Water and Environmental Management 6(1) 1992, 726-731.

[8] Aswani Kumar, Anish Dua, Water quality index for assessment of water quality of River Ravi at Madhopur, India. Global Journal of Environmental Sciences, 8(1), 2009, 49-57. 